\title{
Masseter nerve-based facial palsy reconstruction
}

\author{
Hojin Park, \\ Seong Su Jeong, \\ Tae Suk Oh \\ Department of Plastic and \\ Reconstructive Surgery, Asan Medical \\ Center, University of Ulsan College of \\ Medicine, Seoul, Korea
}

\begin{abstract}
Facial paralysis is a devastating disease, the treatment of which is challenging. The use of the masseteric nerve in facial reanimation has become increasingly popular and has been applied to an expanded range of clinical scenarios. However, appropriate selection of the motor nerve and reanimation method is vital for successful facial reanimation. In this literature review on facial reanimation and the masseter nerve, we summarize and compare various reanimation methods using the masseter nerve. The masseter nerve can be used for direct coaptation with the paralyzed facial nerve for temporary motor input during cross-facial nerve graft regeneration and for double innervation with the contralateral facial nerve. The masseter nerve is favorable because of its proximity to the facial nerve, limited donor site morbidity, and rapid functional recovery. Masseter nerve transfer usually leads to improved symmetry and oral commissure excursion due to robust motor input. However, the lack of a spontaneous, effortless smile is a significant concern with the use of the masseter nerve. A thorough understanding of the advantages and disadvantages of the use of the masseter nerve, along with careful patient selection, can expand its use in clinical scenarios and improve the outcomes of facial reanimation surgery.
\end{abstract}

Keywords: Facial palsy / Facial reanimation / Masseter nerve

\section{INTRODUCTION}

Facial paralysis is a devasting disease, the treatment of which is challenging. The condition has various etiologies and shows a diverse spectrum of presentation and severity. The sequelae of facial palsy include facial asymmetry, oral incompetence, and corneal problems [1]. Moreover, lower facial palsy results in challenges in pronunciation, eating, and saliva control. In addition to functional and morphological impairment, facial palsy may cause psychological distress [2].

Various surgical options are available for facial reanimation. Acute-onset patients with a de-innervation time of less than 2 years generally have excellent outcomes after nerve-based reconstruction, including nerve transfer, nerve grafting, and di-

\footnotetext{
Correspondence: Tae Suk Oh

Department of Plastic and Reconstructive Surgery, Asan Medical Center,

University of Ulsan College of Medicine, 88 Olympic-ro 43-gil, Songpa-gu, Seoul

05505, Korea

E-mail: tasuko@amc.seoul.kr

Received October 20, 2020 / Revised October 20, 2020 / Accepted October 20, 2020
}

rect nerve repair [3]. These procedures allow reinnervation of the native facial muscles, but require sacrificing cranial nerves such as the trigeminal, hypoglossal, and accessory nerves. However, in patients with long-standing facial palsy lasting for more than 2 years, nerve-based reconstruction is unlikely to achieve functional recovery even if reinnervation occurs through nerve transfer because the viability of the motor end-plate is lost. In patients with facial palsy, muscle transfer can be used as a reconstruction method. As well as the timing of facial palsy, the reanimation method is usually chosen based on the surgeon's preference, the patient's age, the etiology of the condition, and facial nerve status.

Spira [4] first introduced the use of the masseter nerve in facial reanimation through free neuromuscular transfer, and this technique has recently become popular; the masseter nerve has also been used in direct coaptation with the paralyzed facial nerve, for temporary motor input in cross-facial nerve graft (CFNG) regeneration, and for double innervation with the contralateral facial nerve. In this study, we present an overview 
of the use of the masseter nerve in facial reanimation.

\section{ANATOMY}

The anterior division of the trigeminal nerve has four branches: the deep temporal, lateral pterygoid, masseteric, and buccal nerves. The masseter nerve is the largest motor branch of the trigeminal nerve [5]. The masseter nerve exits the cranial cavity through the foramen ovale and passes over the lateral pterygoid muscle and through the coronoid notch before entering the masseter muscle [6]. The masseter nerve shows a relatively constant anatomy and has sufficient length, making it a useful motor source in facial reanimation surgery. Brenner and Schoeller [6] reported that the average distance between the coronoid notch and masseter entrance was $32 \mathrm{~mm}$. They also showed that the masseter nerve has two or more branches at the coronoid notch and multiple branches at the level of muscle entry [6]. Thus, masseter nerve transection for motor input in facial reanimation does not result in masseter dysfunction or atrophy, and the nerve has sufficient length for coaptation to the facial nerve branches.

Collar et al. [7] described the subzygomatic triangle, which helps to locate the masseter nerve. The subzygomatic triangle is formed by the inferior border of the zygomatic arch superiorly, and a vertical line through the temporomandibular joint's anterior border and the frontal branch of the facial nerve inferiorly and anteriorly (Fig. 1). The masseter nerve begins at the angle between the temporomandibular joint and zygomatic arch and crosses the midpoint of the triangular base formed by the fron- tal branch of the facial nerve. The authors also reported that this relationship was relatively constant. The nerve is also located $10-15 \mathrm{~mm}$ deep in the parotideomasseteric fascia.

Coombs et al. [8] reported that the masseter nerve contained 1,542.67 axons on average in a series of seven patients undergoing facial nerve palsy surgery. They also found that the nerve to the gracilis muscle had 342 axons and that the masseter nerve had approximately 4.5 times more axons than the obturator nerve. The distal end of the CFNG includes 15 times fewer axons than the masseter nerve [9]. Thus, if CFNG is performed, the CFNG to obturator nerve ratio is approximately 0.5 . To summarize these findings, the masseter nerve has numerous axons and provides powerful and reliable motor signals for facial reanimation.

\section{MASSETER MOTOR NERVE TRANSFER}

Direct transfer of the masseter nerve to the facial nerve is indicated when a single and reliable procedure is required after proximal facial nerve damage caused by conditions such as acoustic neuroma or cerebellopontine angle tumor in patients with a poor general condition [10-12]. Moebius syndrome, multiple cranial neuropathies, facial palsy that has lasted too long to consider CFNG (18-24 months), and unavailability of the contralateral facial nerve are also indications for masseter nerve transfer $[8,13]$.

The concept of nerve transfer for facial reanimation was first introduced in 1903 by Korte et al., who used the hypoglossal
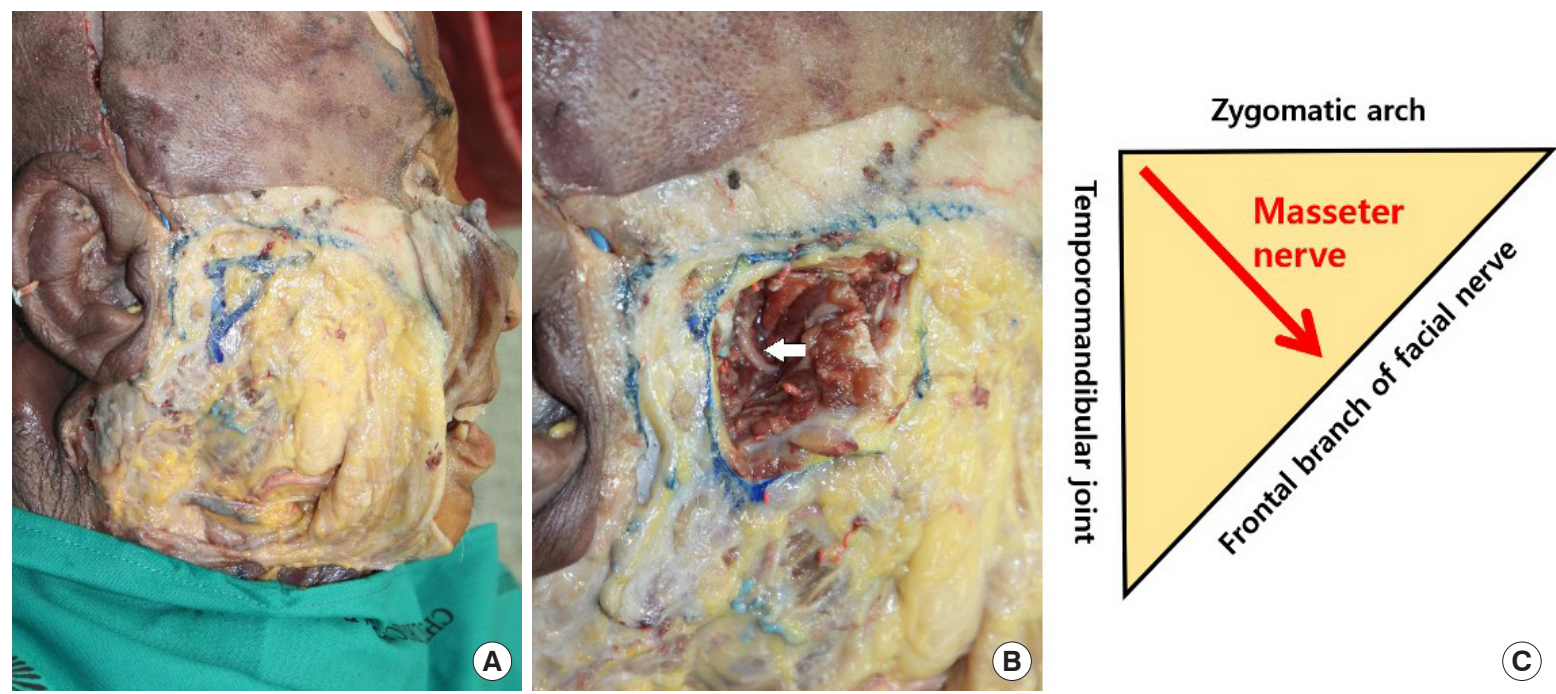

Fig. 1. Subzygomatic triangle. (A) The subzygomatic triangle is formed by the zygomatic arch superiorly, the temporomandibular joint posteriorly, and the frontal branch of the facial nerve anteriorly. (B) The masseter nerve (white arrow) begins at the angle between the temporomandibular joint and zygomatic arch and crosses the midpoint of the triangle base. (C) Schematic diagram of the subzygomatic triangle. 
nerve as a motor input [14]. Although the hypoglossal nerve has been widely used, its disadvantages include hemi-tongue atrophy, resulting in speech and swallowing difficulties. Moreover, most cases require nerve grafts and show synkinetic movements according to tongue movements. Spira [4] first described masseter nerve transfer to lower the division of the facial nerve in 1978 (Fig. 2). The masseter nerve is more favorable than the hypoglossal nerve in terms of its proximity to the facial nerve, limited donor site morbidity, and rapid functional recovery [15-17]. In addition, jaw clenching provokes facial animation, which appears more natural than when tongue movements trigger facial animation, as occurs in hypoglossal nerve transfer [18]. Masseter nerve transfer utilizes the descending branch of the masseter nerve, leaving the proximal branches in-
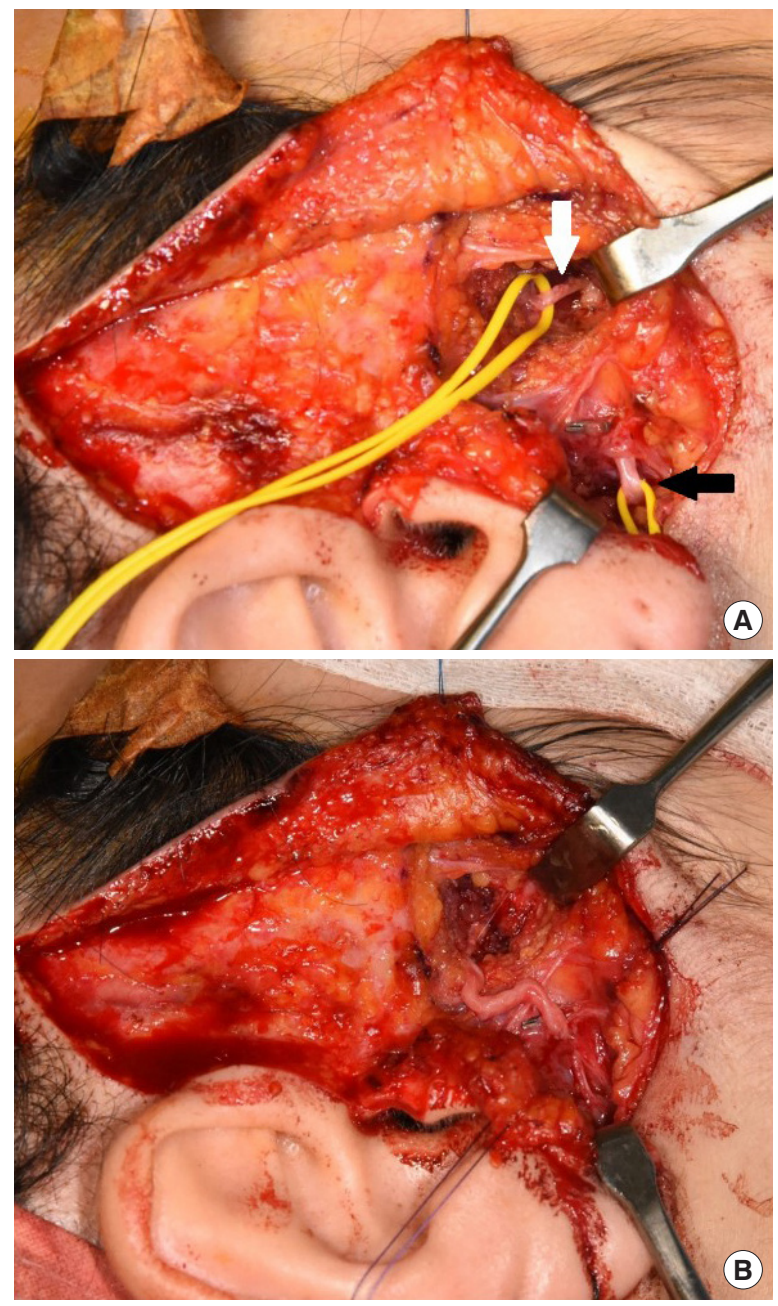

Fig. 2. Masseter nerve transfer to the facial nerve trunk. (A) The facial nerve trunk (black arrow) and masseter nerve (white arrow) are dissected from the surrounding tissues. (B) The masseter nerve is transferred to the facial nerve trunk. The masseter nerve has sufficient length to be coaptated with the facial nerve without the need for a nerve graft. tact. This preservation of the proximal branches prevents masseter muscle atrophy, which produces a hollow around the mandible angle. Moreover, the transposed descending branch of the masseter nerve is sufficiently long to connect to the facial nerve, avoiding the need for nerve grafting [10].

Masseter nerve transfer shows improved symmetry and oral commissure excursion due to the powerful motor input (Fig. 3). Because many studies have used different methods of evaluating facial animation, such as observation-based scores and anthropometric landmark distance, direct comparisons between studies are difficult. However, many studies have reported moderate-to-full facial symmetry after masseter nerve transfer [19]. Albathi et al. [20] measured symmetry using the difference in the distance between the medial canthus and oral com-
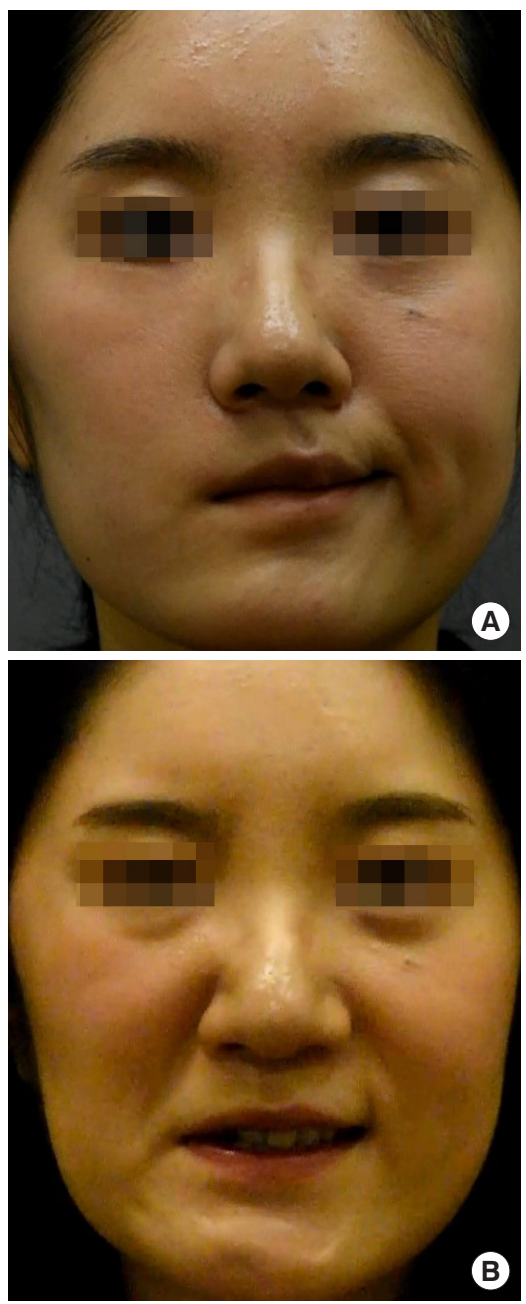

Fig. 3. A case of masseter to facial nerve transfer. A 23-year-old woman presented with complete right-side facial palsy after vestibular schwannoma excision. The denervation period was 2 months and the patient underwent transfer of the masseter nerve to the facial nerve trunk. Preoperative (A) and 4-month postoperative (B) smile excursion photographs are shown. 
missure, and reported a mean oral commissure difference of $1.7 \pm 1.4 \mathrm{~mm}$ at rest and $10.6 \pm 5.0 \mathrm{~mm}$ while smiling.

The time to nerve recovery is approximately 5 months (range, 2-7 months) [19]. This time varies according to the nerve coaptation site and the definition of nerve recovery. In a previous study, nerve recovery was defined as the first contraction [21], while in another study, it was defined as facial symmetry [22]. Masseter nerve transfer to the zygomatic/buccal branch showed a faster recovery time than that to the facial trunk (3.76 months vs. 5.76 months) [19]. An explanation for this difference is that the main trunk is further away than the zygomatic/buccal branches; hence, more time is needed for regeneration. Masseter nerve transfer shows rapid nerve regeneration potential. Thus, it can be used for transient motor input before CFNG; this is termed the babysitter technique, and is discussed later in this study.

A spontaneous, effortless, and unconscious smile is a major concern regarding masseter nerve transfer to the facial nerve. Hontanilla and Cabello [23] reported a series of 30 patients treated with masseter nerve transfer, of whom 17 (56\%) achieved a spontaneous smile. Although the proportions of spontaneous smiles differ in the literature, it has been reported that about $80 \%$ of patients learned to smile without biting and $40 \%-60 \%$ showed spontaneous smiles [10]. Cortical plasticity plays an essential role in cortical adaptation and spontaneous activation of the fifth cranial nerve. This phenomenon has been studied using neuroimaging techniques that confirmed cortical plasticity after masseter nerve transfer; however, few cases are available [24]. Therefore, the possibility of achieving a spontaneous smile after masseter nerve transfer remains controversial and is still considered hypothetical.

\section{BABYSITTER AND DOUBLE INNERVATION PROCEDURES}

The use of the contralateral healthy facial nerve as a donor nerve provides a spontaneous, emotional, and natural smile [25]. The contralateral facial nerve, if applicable, is considered to be the best choice in facial reanimation due to its spontaneity and synchronicity of facial expression. Scaramella [26] first introduced the CFNG in 1971 for reanimation in cases of acquired unilateral facial palsy. Since then, the use of CFNG has become popular and several modified methods have been proposed. However, CFNG requires an extended time for the regeneration of axons through the grafted nerve. This prolongs the denervated and unstimulated time of the facial muscles, which in turn results in irreversible facial muscle atrophy and a lower likelihood of successful facial reanimation.
In 1984, Kalantarian et al. [27] introduced a babysitter procedure in which the hypoglossal nerve is temporarily used with the CFNG to prevent muscle atrophy and maintain muscle tone during CFNG nerve regeneration. The hypoglossal nerve is coaptated to the facial nerve branches, and the distal end of the CFNG is left in the preauricular area without suturing it to the paralyzed-side facial nerve. In the second stage of the procedure, the babysitter nerve is removed and the regenerated CFNG is transposed to the facial nerve branches [28,29]. The hypoglossal nerve is the first choice and is commonly used in the babysitter procedure.

As a babysitter, the hypoglossal nerve yields successful results, but often shows unpredictable and unreliable results due to its mild motor input. Moreover, tongue atrophy and movement impairment can occur after the use of the hypoglossal nerve [16]. The masseter nerve has been used as an alternative in the babysitter procedure. The masseter nerve yields predictable, reliable results with robust motor input. The powerful impulse allows a symmetric excursion of the oral commissure, which is very difficult to achieve with other motor nerves. When the masseter nerve is used in the babysitter procedure, the nerve is not usually removed in the second stage. This double innervation procedure increases the extent of facial muscle contraction [17]. Double innervation of the masseter nerve and CFNG enables the procedure to be completed in a single stage by connecting the CFNG to the middle and upper third of the facial nerve and the masseter nerve to the lower third [30]. In a study by Bianchi et al. [31], double innervation resulted in rapid and powerful contractions. They also reported contraction of the lower-third of the facial area after 3 months and in other areas after 10.5 months [16].

\section{NEUROMUSCULAR TRANSPLANTATION}

Free muscle transfer may be considered if nerve transfer is not available due to muscle atrophy in patients with long-term facial palsy (injuries that have lasted for more than 2 years) or congenital facial paralysis [32]. The temporalis and gracilis muscles are commonly used in neuromuscular transplantation. The trigeminal nerve also innervates the temporalis muscle, but it is unresponsive to emotion without extensive training. Thus, the temporalis transposition lacks spontaneous movement and results in bulk over the zygomatic arch [33]. The gracilis muscle, which is long and thin, is used to produce smile excursion in patients with facial palsy. Many studies have reported symmetric and dynamic results after free gracilis muscle transposition [34]. In free neuromuscular transplantation, the ipsilateral 
masseter and contralateral facial nerves are commonly chosen as motor inputs. As with direct nerve transfer, each nerve has similar advantages and disadvantages when used as a neurotizer in free neuromuscular transfer (Fig. 4).

The masseter nerve is preferred in specific situations such as Moebius syndrome. Furthermore, bilateral facial palsy, old age (>70 years), and primary CFNG failure are indications for masseter nerve and free gracilis muscle transfer [35]. The use of the masseter nerve in neuromuscular transfer provides various advantages [36]. For instance, a one-stage procedure is possible with a high axonal load, resulting in strong commissure excursion and good symmetry (Fig. 5). The masseter nerve is also located near the facial nerve branches. Additional dissection is not usually required to find a motor nerve. Since there is no need for a nerve graft due to the close location of the masseter nerve and the transferred muscle inset site, motor signal loss through the two coaptation sites can be avoided [37]. However, gracilis muscle transfer with coaptation to the masseter nerve often results in involuntary unwanted movement during normal mastication. The degree of involuntary movement varies, although even weak involuntary movement is observed during mastication in many patients. Nevertheless, it is not clinically meaningful and patients do not complain of discomfort [38].

The CFNG and the masseter nerve can also be combined for double innervation. Watanabe et al. [39] first introduced the use of one-stage free neuromuscular transposition with double
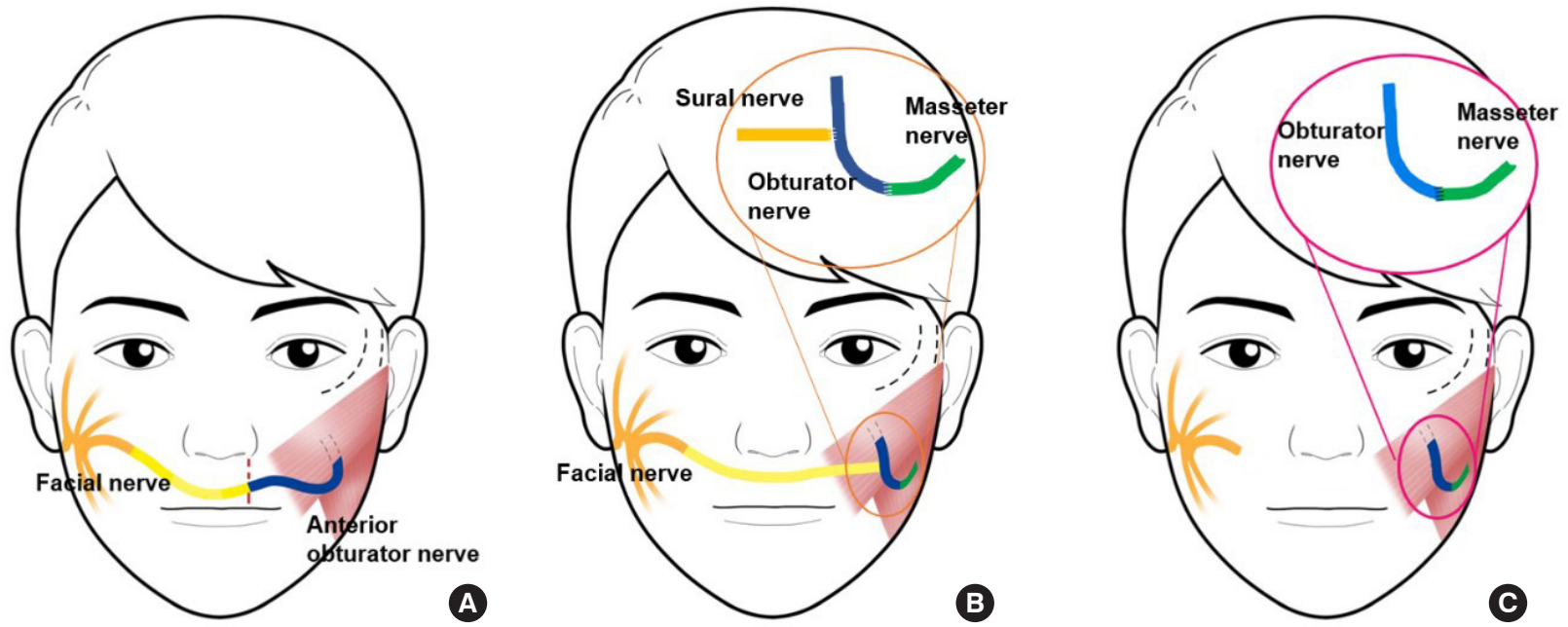

Fig. 4. Commonly used neurotizers in free gracilis muscle transfer. (A) Cross-facial nerve graft. (B) Double innervation. (C) Masseter nerve.
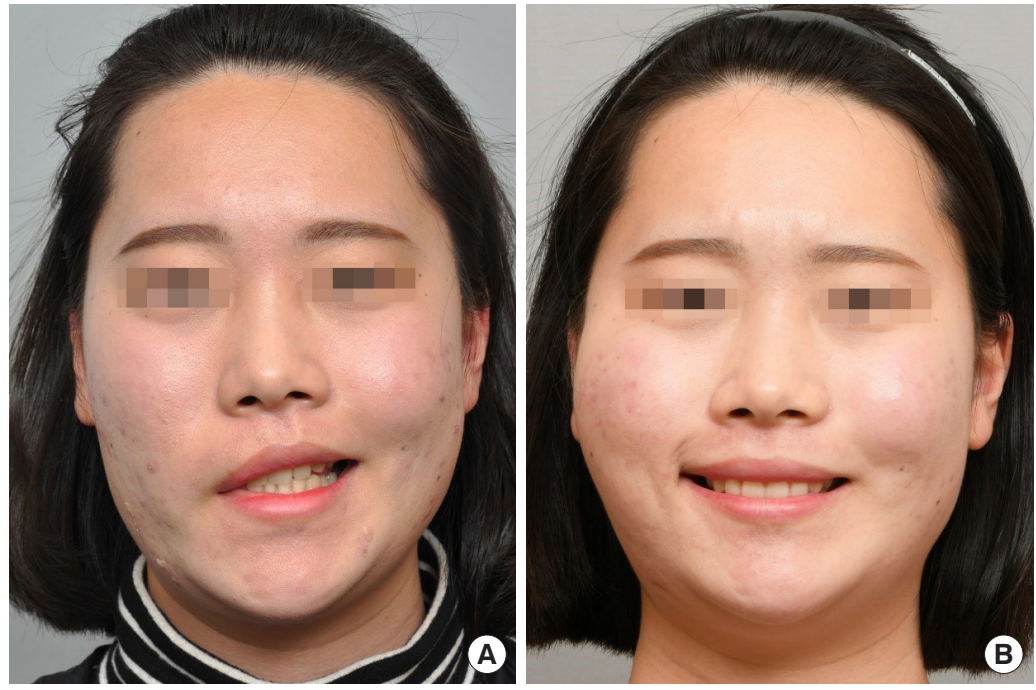

Fig. 5. A case of free gracilis muscle transfer. A 21-year-old woman with right congenital complete facial paralysis underwent facial reanimation with free gracilis muscle transfer. The left-side of the masseter nerve was used as a neurotizer. (A) Preoperative smile. (B) Eight months after facial reanimation surgery. 
innervation. They reported a series of latissimus dorsi muscle transfers with double innervation that achieved a spontaneous smile and facial symmetry. Double innervation may be an ideal option, as the masseter nerve provides sufficient motor impulse, while CFNG allows a more spontaneous and emotional smile excursion. Kim et al. [40] compared the results of CFNG alone and double innervation after free gracilis muscle transfer. They concluded that the double-innervated gracilis provided more symmetric results during smiling; however, the two methods showed similar results at rest. In double innervation, controversy exists regarding which nerve acts as the primary motor input for smile excursion. Biglioli et al. [30] performed a nerve conduction study in patients with double-innervated gracilis muscle transfer using a coaxial needle. Although they demonstrated the excitability of the CFNG, they were unable to check the masseter nerve due to artifacts. Hence, further studies are needed to identify which nerve is the main neurotizer.

In their systematic review and meta-analysis of the surgical outcomes of dynamic gracilis muscle transfer, Roy et al. [41] reported that use of the masseter nerve was associated with greater smile excursion than the use of CFNG ( $10.0 \mathrm{~mm}$ vs. 6.8 $\mathrm{mm}$ ). However, CFNG generally produces a more spontaneous, emotional smile despite its reduced commissure movement. CFNG has a weak contraction power and requires extended rehabilitation. It generally takes 12-24 months to reach moderate smile excursion and achieve optimal facial movements [35]. However, CFNG provides the opportunity to achieve a naturallooking smile. The masseter nerve can produce rapid results, with early movement of the transferred muscle occurring at 3-6 months after surgery. Although the muscle contraction is strong, the smile does not look natural. Moreover, smile training is necessary to move without jaw clenching.

\section{CONCLUSION}

The use of the masseter nerve has become popular in facial reanimation. The advantages of the use of the masseter nerve include ease of dissection, proximity to the facial nerve, low donor site morbidity, a powerful motor impulse, and relatively short reinnervation time. However, the disadvantages include the low rate of spontaneous smile recovery. Only $40 \%-60 \%$ of patients achieve an emotional, spontaneous smile. However, most patients learn voluntary smiles without biting, a rate higher than that reported with the use of other cranial nerves or temporalis transfer. Thus, careful patient selection and consideration of the advantages and disadvantages of the use of the masseter nerve are necessary to achieve satisfactory results.

\section{NOTES}

\section{Conflict of interest}

No potential conflict of interest relevant to this article was reported.

\section{Ethical approval}

The study was approved by the Institutional Review Board of Asan Medical Center (IRB No. 2019-0166) and performed in accordance with the principles of the Declaration of Helsinki. Written informed consent was obtained for the publication.

\section{Patient consent}

The patients provided written informed consent for the publication and the use of their images.

\section{ORCID}

Hojin Park

https://orcid.org/0000-0001-9809-0558

Seong Su Jeong

Tae Suk Oh

https://orcid.org/0000-0001-9130-1148

https://orcid.org/0000-0001-8174-8915

\section{REFERENCES}

1. Nguyen PD, Faschan KS, Mazzaferro DM, Konieczny T, Jackson OA, Bartlett SP. Comparison of lengthening temporalis myoplasty and free-gracilis muscle transfer for facial reanimation in children. J Craniofac Surg 2020;31:85-90.

2. Bylund N, Hultcrantz M, Jonsson L, Marsk E. Quality of life in Bell's palsy: correlation with Sunnybrook and House-Brackmann over time. Laryngoscope 2020 May 28 [Epub]. https:// doi.org/10.1002/lary.28751.

3. Garcia RM, Hadlock TA, Klebuc MJ, Simpson RL, Zenn MR, Marcus JR. Contemporary solutions for the treatment of facial nerve paralysis. Plast Reconstr Surg 2015;135:1025e-1046e.

4. Spira M. Anastomosis of masseteric nerve to lower division of facial nerve for correction of lower facial paralysis: preliminary report. Plast Reconstr Surg 1978;61:330-4.

5. Fournier HD, Denis F, Papon X, Hentati N, Mercier P. An anatomical study of the motor distribution of the mandibular nerve for a masseteric-facial anastomosis to restore facial function. Surg Radiol Anat 1997;19:241-4.

6. Brenner E, Schoeller T. Masseteric nerve: a possible donor for facial nerve anastomosis? Clin Anat 1998;11:396-400.

7. Collar RM, Byrne PJ, Boahene KD. The subzygomatic triangle: rapid, minimally invasive identification of the masseteric nerve for facial reanimation. Plast Reconstr Surg 2013;132:183-8.

8. Coombs CJ, Ek EW, Wu T, Cleland H, Leung MK. Massetericfacial nerve coaptation: an alternative technique for facial nerve 
reinnervation. J Plast Reconstr Aesthet Surg 2009;62:1580-8.

9. Frey M, Happak W, Girsch W, Bittner RE, Gruber H. Histomorphometric studies in patients with facial palsy treated by functional muscle transplantation: new aspects for the surgical concept. Ann Plast Surg 1991;26:370-9.

10. Klebuc MJ. Facial reanimation using the masseter-to-facial nerve transfer. Plast Reconstr Surg 2011;127:1909-15.

11. Cho HR, Kwon SS, Chung S, Choi YJ. Intraparotid facial nerve schwannoma. Arch Craniofac Surg 2014;15:28-31.

12. Hwang JH, Lee DG, Sim HS, Kim KS, Lee SY. Intramasseteric schwannoma treated with facelift incision and retrograde facial nerve dissection. Arch Craniofac Surg 2019;20:388-91.

13. Hontanilla B, Marre D. Comparison of hemihypoglossal nerve versus masseteric nerve transpositions in the rehabilitation of short-term facial paralysis using the Facial Clima evaluating system. Plast Reconstr Surg 2012;130:662e-672e.

14. Campero A, Socolovsky M. Facial reanimation by means of the hypoglossal nerve: anatomic comparison of different techniques. Neurosurgery 2007;61(3 Suppl):41-50.

15. Bae YC, Zuker RM, Manktelow RT, Wade S. A comparison of commissure excursion following gracilis muscle transplantation for facial paralysis using a cross-face nerve graft versus the motor nerve to the masseter nerve. Plast Reconstr Surg 2006; 117:2407-13.

16. Bianchi B, Ferri A, Ferrari S, Copelli C, Magri A, Ferri T, et al. Cross-facial nerve graft and masseteric nerve cooptation for one-stage facial reanimation: principles, indications, and surgical procedure. Head Neck 2014;36:235-40.

17. Faria JC, Scopel GP, Ferreira MC. Facial reanimation with masseteric nerve: babysitter or permanent procedure? Preliminary results. Ann Plast Surg 2010;64:31-4.

18. Biglioli F, Colombo V, Rabbiosi D, Tarabbia F, Giovanditto F, Lozza A, et al. Masseteric-facial nerve neurorrhaphy: results of a case series. J Neurosurg 2017;126:312-8.

19. Murphey AW, Clinkscales WB, Oyer SL. Masseteric nerve transfer for facial nerve paralysis: a systematic review and meta-analysis. JAMA Facial Plast Surg 2018;20:104-10.

20. Albathi M, Oyer S, Ishii LE, Byrne P, Ishii M, Boahene KO. Early nerve grafting for facial paralysis after cerebellopontine angle tumor resection with preserved facial nerve continuity. JAMA Facial Plast Surg 2016;18:54-60.

21. Oh TS, Kim HB, Choi JW, Jeong WS. Facial reanimation with masseter nerve-innervated free gracilis muscle transfer in established facial palsy patients. Arch Plast Surg 2019;46:122-8.

22. Chen G, Wang W, Wang W, Ding W, Yang X. Symmetry restoration at rest after masseter-to-facial nerve transfer: is it as efficient as smile reanimation? Plast Reconstr Surg 2017;140:793801.
23. Hontanilla B, Cabello A. Spontaneity of smile after facial paralysis rehabilitation when using a non-facial donor nerve. J Craniomaxillofac Surg 2016;44:1305-9.

24. Manktelow RT, Tomat LR, Zuker RM, Chang M. Smile reconstruction in adults with free muscle transfer innervated by the masseter motor nerve: effectiveness and cerebral adaptation. Plast Reconstr Surg 2006;118:885-99.

25. Frey M, Giovanoli P. The three-stage concept to optimize the results of microsurgical reanimation of the paralyzed face. Clin Plast Surg 2002;29:461-82.

26. Scaramella LF. Anastomosis between the two facial nerves. Laryngoscope 1975;85:1359-66.

27. Kalantarian B, Rice DC, Tiangco DA, Terzis JK. Gains and losses of the XII-VII component of the "baby-sitter" procedure: a morphometric analysis. J Reconstr Microsurg 1998;14:459-71.

28. Terzis JK, Tzafetta K. The "babysitter" procedure: minihypoglossal to facial nerve transfer and cross-facial nerve grafting. Plast Reconstr Surg 2009;123:865-76.

29. Mersa B, Tiangco DA, Terzis JK. Efficacy of the "baby-sitter" procedure after prolonged denervation. J Reconstr Microsurg 2000;16:27-35.

30. Biglioli F, Colombo V, Tarabbia F, Pedrazzoli M, Battista V, Giovanditto F, et al. Double innervation in free-flap surgery for long-standing facial paralysis. J Plast Reconstr Aesthet Surg 2012;65:1343-9.

31. Bianchi B, Ferri A, Ferrari S, Copelli C, Salvagni L, Sesenna E. The masseteric nerve: a versatile power source in facial animation techniques. Br J Oral Maxillofac Surg 2014;52:264-9.

32. Tate JR, Tollefson TT. Advances in facial reanimation. Curr Opin Otolaryngol Head Neck Surg 2006;14:242-8.

33. Conley J, Baker DC, Selfe RW. Paralysis of the mandibular branch of the facial nerve. Plast Reconstr Surg 1982;70:569-77.

34. Chuang DC, Mardini S, Lin SH, Chen HC. Free proximal gracilis muscle and its skin paddle compound flap transplantation for complex facial paralysis. Plast Reconstr Surg 2004;113: 126-35.

35. Chuang DC, Lu JC, Chang TN, Laurence VG. Comparison of functional results after cross-face nerve graft-, spinal accessory nerve-, and masseter nerve-innervated gracilis for facial paralysis reconstruction: the Chang Gung experience. Ann Plast Surg 2018;81(6S Suppl 1):S21-9.

36. Henstrom DK. Masseteric nerve use in facial reanimation. Curr Opin Otolaryngol Head Neck Surg 2014;22:284-90.

37. Hontanilla B, Olivas J, Cabello A, Marre D. Cross-face nerve grafting versus masseteric-to-facial nerve transposition for reanimation of incomplete facial paralysis: a comparative study using the FACIAL CLIMA evaluating system. Plast Reconstr Surg 2018;142:179e-191e. 
38. Rozen S, Harrison B. Involuntary movement during mastication in patients with long-term facial paralysis reanimated with a partial gracilis free neuromuscular flap innervated by the masseteric nerve. Plast Reconstr Surg 2013;132:110e-116e.

39. Watanabe Y, Akizuki T, Ozawa T, Yoshimura K, Agawa K, Ota T. Dual innervation method using one-stage reconstruction with free latissimus dorsi muscle transfer for re-animation of established facial paralysis: simultaneous reinnervation of the ipsilateral masseter motor nerve and the contralateral facial nerve to improve the quality of smile and emotional facial expressions. J Plast Reconstr Aesthet Surg 2009;62:1589-97.
40. Kim MJ, Kim HB, Jeong WS, Choi JW, Kim YK, Oh TS. Comparative study of 2 different innervation techniques in facial reanimation: cross-face nerve graft-innervated versus doubleinnervated free gracilis muscle transfer. Ann Plast Surg 2020; 84:188-95.

41. Roy M, Corkum JP, Shah PS, Borschel GH, Ho ES, Zuker RM, et al. Effectiveness and safety of the use of gracilis muscle for dynamic smile restoration in facial paralysis: a systematic review and meta-analysis. J Plast Reconstr Aesthet Surg 2019;72: 1254-64. 